\title{
Erratum to: Salinity tolerance of hydroponically grown Pinus pinea L. seedlings
}

\author{
Abdelhamid Khaldi • Rebai Ben Ammar • \\ Su Young Woo $\cdot$ Noureddine Akrimi • \\ Ezzeddine Zid
}

Published online: 8 October 2010

(C) Franciszek Górski Institute of Plant Physiology, Polish Academy of Sciences, Kraków 2010

\section{Erratum to: Acta Physiol Plant \\ DOI 10.1007/s11738-010-0601-z}

This article contains a co-corresponding author, Su Young Woo apart from the corresponding author.

The article note which was missed in the original publication should read as "Corresponding and co-corresponding authors have equal contribution for this paper".

The online version of the original article can be found under doi:10.1007/s11738-010-0601-z.

A. Khaldi · R. B. Ammar

Unit of Research on Management and Valorization of Forest

Resources, National Institute of Research on Rural Engineering,

Water and Forests, INRGREF-BP 10, 2080 Ariana, Tunisia

R. B. Ammar · E. Zid

Unit of Ecophysiology and Plant Nutrition,

Department of Biology, Faculty of Sciences of Tunis,

University of Tunis-El-Manar, 1060 Tunis, Tunisia

S. Y. Woo $(\square)$

Department of Environmental Horticulture,

University of Seoul, Seoul 130-743, Korea

\section{A. Khaldi $(\square) \cdot$ N. Akrimi}

Department of GREF, National Institute of Agronomy

of Tunisia, 43, Street of Charles Nicolle,

1082 Tunis, Tunisia

e-mail: khaldi.abdelhamid@iresa.agrinet.tn

\section{R. B. Ammar}

Department of Bioactive Substances,

Center of Biotechnology of Borj Cedria,

PB 901, 2050 Hammam-Lif, Tunisia 